\title{
KAJIAN PENGARUH SEBARAN TACK COAT TERHADAP KEKUATAN GESER PADA LAPISAN PERKERASAN JALAN
}

\author{
Muthia Anggraini \\ Program Studi Teknik Sipil, Fakultas Teknik, Universitas Lancang Kuning \\ Jl. Yos Sudarso Km. 8 Pekanbaru \\ E-mail : muthia@unilak.ac.id \\ Alfian Saleh \\ Program Studi Teknik Sipil, Fakultas Teknik, Universitas Lancang Kuning \\ Jl. Yos Sudarso Km. 8 Pekanbaru \\ E-mail : alfian.saleh@gmail.com \\ Hendri Rahmat \\ Program Studi Teknik Sipil, Fakultas Teknik, Universitas Lancang Kuning \\ Jl. Yos Sudarso Km. 8 Pekanbaru \\ E-mail : hendri.rahmat1973@yahoo.co.id
}

\begin{abstract}
Abstrak
Pemeliharaan jalan pada perkerasan lentur dapat dilakukan dengan overlay. Overlay mengakibatkan perkerasan lentur menjadi beberapa lapisan material beraspal. Untuk melakukan overlay diberi lapisan tack coat antara lapisan lama dengan lapisan baru. Fungsi dari tack coat adalah sebagai perekat antar lapisan, selain itu juga untuk menahan gaya geser yang terjadi diantara lapis perkerasan akibat dari beban kendaraan. Penelitian ini bertujuan untuk mengetahui perilaku lekatan tack coat dengan variasi sebaran tack coat 0,$25 ; 0,30 ; 0,35$; dan $0,45 \mathrm{ltr} / \mathrm{m}^{2}$ pada lapisan perkerasan jalan. Metodologi yang digunakan yaitu pengujian laboratorium dengan menggunakan alat uji geser langsung untuk menentukan kuat geser tack coat. Hasil penelitian menunjukkan nilai kuat geser meningkat sampai takaran tack coat 0,35 $1 \mathrm{tr} / \mathrm{m}^{2}$, dan nilainya turun pada takaran $0,45 \mathrm{ltr} / \mathrm{m}^{2}$. Kesimpulannya kuat geser pada lapisan perkerasanakan makin tinggi apabila jumlah takaran tack coat makin tinggi, dan kuat geser akan turun pada takaran $0,45 \mathrm{ltr} / \mathrm{m}^{2}$.
\end{abstract}

Kata Kunci :Tack coat, Kekuatan geser, Campuran AC-WC

\begin{abstract}
Road maintenance on flexible pavement can be done by overlaying. Overlay resulted in flexible pavements in several layers of paving material. To overlay a layer of tack coat between the old layer and the new layer. The function of the tack coat is as an adhesive between layers, in addition to holding the sheer force that occurs between the pavement layers due to the load of the vehicle. This study aims to determine the behavior of tack coat attachment with variations in the
\end{abstract}


Angraini, M., Saleh, A., Rahmat, H. / Kajian pengaruh Sebaran Tack Coat/ pp. 23-30

distribution of tack coat $0.25 ; 0.30 ; 0.35$; and $0.45 \mathrm{ltr} / \mathrm{m}^{2}$ on the pavement layer.The methodology used is laboratory testing using a direct shear tester to determine the shear strength of the tack coat. The results showed that the value of shear strength increased until the tack coat dose was $0.35 \mathrm{ltr} / \mathrm{m}^{2}$, and the value dropped at a dose of $0.45 \mathrm{ltr} / \mathrm{m}^{2}$. In conclusion, the shear strength on the pavement layer will be higher if the amount of tack coat dose is higher, and the shear strength will drop at a dose of $0.45 \mathrm{ltr} / \mathrm{m}^{2}$.

Keywords: Tack coat, Shear Strength, Mixed AC-WC

\section{A. PENDAHULUAN}

Overlay sering dilakukan untuk pemeliharaan jalan, sehingga perkerasan lentur sering mengalami beberapa kali overlay sehingga terdiri dari beberapa lapisan material aspal.

Antar lapis material beraspal tersebut diberi lapisan tack coat sebagai perekat antar lapisannya. Campuran beraspal, baru diberikan setelah beberapa saat setelah pemberian tack coat, hal ini dimaksudkan untuk memberikan kesempatan pada minyak yang terdapat pada tack coat untuk menguap.

Spesifikasi penggunaan jumlah tack coat pada perkerasan beraspal masih sangat bervariasi dari segi penyebarannya dan bahan yang digunakan. Faktor yang mempengaruhi penggunaan tack coat yaitu: bahan tack coat itu sendiri, kondisi permukaan perkerasan, dan iklim dari daerah tersebut. Penggunaan tack coat yang terlalu sedikit akan mengakibatkan mudah lepasnya ikatan antar lapisan perkerasan lama dan baru. Sedangkan apabila pemberian tack coat terlalu berlebih dikhawatirkan akan akan membentuk bidang geser antar lapisannya. Sehingga pemberian tack coat yang tepat akan sangat membantu kinerja antara lapisan perkerasan beraspal.

Di lapangan adakalanya takaran sebaran pemberian tack coat tidak merata pada seluruh lapisan perkerasan. Hal ini berdampak pada lekatan antara perkerasan lama dengan perkerasan baru yang tidak merata. Permasalahan di lapangan kuat geser lapis perkerasan yang dilapisi tack coat tergantung dari campuran tack coat dan cara pelaksanaan penghamparan tack coat. Ikatan lapisan yang baik antara tack coat dan dengan campuran aspal akan menghilangkan tekanan lalu lintas dari satu lapisan ke lapisan berikutnya, sementara ikatan yang tidak memadai dan ditambah dengan kondisi beban yang tidak menguntungkan dapat menyebabkan kerusakan dini pada perkerasan (Wang, 2017).

Pada penelitian ini penulis akan mengkaji mengenai pemberian sebaran tack coat 0,$25 ; 0,30 ; 0,35$; dan 0,45 $1 \mathrm{tr} / \mathrm{m}^{2}$, yang kemudian dikaitkan dengan daya lekat antara lapisan perkerasan lama dengan yang baru.

Dari permasalahan diatas penulis ingin mengkaji perilaku lekatan tack coat pada lapisan perkerasan dengan variasi curring time. Perbedaan penelitian ini dengan yang sebelumnya yaitu menentukan kuat geser pengaruh sebaran tack coat dengan variasi curring time. Spesifikasi Umum Departemen Pekerjaan Umum Dirjen Bina Marga tahun 2010, dimana takaran sebesar 0,15 - 0,35 $\mathrm{ltr} / \mathrm{m}^{2}$ untuk permukaan porous. Judul dari penelitian ini adalah ini Pengaruh Sebaran Takaran Tack Coat Pada Perilaku Lapisan Perkerasan.

Penelitian terdahulu yaitu Penelitian Sudenroy Mentang, Bonny F.S, dan Freddy Jansen (2014) 
mengetahui setting time pada variasi komposisi campuran tack coat akibat pengaruh air yang memberikan nilai kuat geser maksimum. Penelitian Atmy Verani Rouly Sihombing (2014) mengetahui daya rekat tack coat akibat penundaan waktu selama lebih dari 5 jam dan dipanaskan kembali hingga mencapai temperatur tack coat yang bervariasi sebelum lapisan jalan baru dihamparkan. Dilakukan terhadap lekatan HRS-WC aspal pen 60, dengan kadar aspla 8,5\%. Penelitian Wellem Toad dan JoiceE, Waani (2016) untuk mengetahui bagaimana hubungan curing time dan kuat geser tack coat terhadap variasi suhu permukaan jalan, setting time dari setiap suhu permukaan jalan dan curing time 30 menit, 45 menit, 60 menit, 75 menit, 90 menit,105 menit,120 menit dan 135 menit dan variasi suhu yaitu $20^{\circ} \mathrm{C}, 30^{\circ} \mathrm{C}, 40^{\circ} \mathrm{C}$, $50^{\circ} \mathrm{C}$ dan $60^{\circ} \mathrm{C}$.

\section{Tujuan Penelitian}

Tujuan penelitian ini adalah untuk mengetahui perilaku lekatan tack coat dengan sebaran tack coat 0,25; 0,30; 0,35; dan $0,451 \mathrm{tr} / \mathrm{m}^{2}$ terhadap lapisan perkerasan.

\section{Manfaat penelitian}

Penelitian ini diharapkan dapat memberikan informasi tentang lapisan tack coat dan memberikan masukan dalam ilmu perkerasan jalan.

\section{A. TINJAUAN PUSTAKA \\ 1. Lapis Perkerasan Jalan}

Perkerasan jalan adalah campuran antara agregat dan bahan ikat yang digunakan untuk melayani beban lalu lintas. Agregat yang dipakai antara lain adalah batu pecah, batu belah, batu kali dan hasil samping peleburan baja. Sedangkan bahan ikat yang dipakai antara lain adalah aspal, semen dan tanah liat. Bahan perkerasan jalan adalah campuran antara agregat dan bahan pengikat (aspal atau semen). Bila menggunakan bahan pengikat aspal disebut jenis campuran fleksibel dan bila menggunakan semen disebut jenis campuran kaku (Sunarjono, 2006).

Bahan perkerasan jalan didisain untuk mencapai properties tertentu sesuai

spesifikasi yang disyaratkan. Masing-masing lapis perkerasan (lapis wearing course, binder course atau base course) mempunyai spesifikasi khusus sesuai karakter fungsional dan strukturalnya berbeda. Campuran jenis fleksibel dapat dibuat dengan 3 (tiga) cara yaitu (Sunarjono, 2006) :

1. Pencampuranpanas (hot-mix asphalt, HMA)

2. Pencampuranhangat (warm-mix asphalt, WMA)

3. Pencampurandingin (cold-mix asphalt, CMA).

Berdasarkan bahan pengikatnya, konstruksi perkerasan jalan dapat dibedakan atas (Sukirman, 2003) :

a. Konstruksi perkerasan lentur (Flexible Pavement), yaitu perkerasan yang menggunakan aspal sebagai bahan pengikatnya. Lapisanlapisan perkerasan bersifat memikul dan menyebarkan beban lalu lintas ke tanah dasar.

b. Konstruksi perkerasan kaku (Rigit Pavement), yaitu perkerasan yang menggunakan semen (Portland Cement) sebagai bahan pengikatnya. Pelat beton dengan atau tanpa tulangan diletakkan diatas tanah dasat dengan atau tanpa lapis pondasi bawah. Beban lalu lintas sebagian besar dipikul oleh pelat beton.

c. Konstruksi perkerasan komposit (Composite Pavement), yaitu perkerasan kaku yang dikombinasikan dengan perkerasan lentur dapat berupa perkerasan 
Angraini, M., Saleh, A., Rahmat, H. / Kajian pengaruh Sebaran Tack Coat/ pp. 23-30

lentur diatas perkerasan kaku atau perkerasan kaku diatas perkerasan lentur.

\section{Lapisan Perekat (Tack Coat)}

Tack Coat adalah lapisan tipis aspal yang memberikan daya rekat sekaligus memberikan kekuatan diantara lapisanperkerasan lama dengan lapisan perkerasan baru (Mentanget al, 2014). Umumnya asphaltbinder, cut-back asphalt, dan aspal emulsi digunakan sebagai material Tack Coat, namun yang banyak digunakan adalah aspal emulsi (Zhang, 2017)

Tack coat yang terbentuk dari bahan aspal emulsi adalah jenis Rapid Setting dengan bahan pengencer air dan pelarut atau dari bahan aspal cair (cut aspal) dengan bahan pengencer (solvent) yang mudah.Besaran sebaran takaran tack coatbergantung pada kondisi permukaan konstruksi jalan lama (existing),mulai dari $0,15-0,35$ $1 \mathrm{tr} / \mathrm{m} 2$ dengan temperature $110+100 \mathrm{C}$. Lapisan tackcoat berfungsi sebagai lapisan perekat antara lapisan perkerasan lama dengan lapisan perkerasan baru sehingga memberikan daya rekatyang kuat. Pelaburan tack coat dilakukandengan menggunakan aspal distributor atau aspalsprayer dengan mengatur posisi nozzle danketinggian tongkat nozzle sedemikian rupasehingga laburan tack coat akan merata sesuaidengan takaran sebaran yang diisyarakatkan(Mentang, Sompie, \& Jansen, 2014)

Lapis perekat berfungsi untuk memberikan daya ikat antara lapis lama dengan baru, dan dipasanag pada permukaan beraspal atau beton semen yang kering dan bersih. Menurut spesifikasi 2010 revisi 2 lapis perekat harus dihampar diatas permukaan berbahan pengikat seperti: Lapis Penetrasi Macadam, Laston, Lataston dan diatas semen tanah, dan lain lain.Bahan lapisan perekat adalah :

1. Aspalemulsireaksicepat (rapid setting) yang memenuhi SNI 036932-2002 atau SNI 03-4798-1998.

2. Aspal semen Pen.60/70 atau Pen.80/100 memenuhiketentuan AASTHO

M20, diencerkandengan 25-30 bagianminyaktanah per 100 bagianaspal (25 pph-30 pph).

3. Aspalemulsimodifikasireaksicepat (rapid setting) harusbahanstyrene butadiene rubber latex ataupolycholoprene latexatausesuaidengan M316-99 (2003).

Bahan pengencer/pelarut cutback aspal ada 3 jenis yaitu :

1. Jenis Rapid curing cutback, dimana aspal semen dilarutkan dengan bahan pengencer bensin. RC merupakan cutback aspal yang paling cepat menguap.

2. Jenis Medium curing cutback, dimana aspal sement dilarutkan dengan bahan pengencer yang lebih kental seperti minyak tanah/kerosin. Jenis MC ini banyak digunakan dikarenakan harganya yang relatif murah juga disebabkan karena minyak tanah tidak cepat menguap sehingga memberikan kemudahan dalam pekerjaan (workability) serta memberikan ketelitian dalam penelitian.

3. Jenis Slow curing cutback, dimana aspal semen dilarutkan dengan bahan yang lebih kental seperti solar. Aspal jenis SC ini merupakan cutback aspal yang paling lama menguap, sehingga sangat jarang digunakan dalam pekerjaan pengaspalan.

Sesuai dengan jenis permukaan yang akan menerima pelaburan dan jenis bahan aspal yang akan dipakai, 
berikut adalah tabel 1 jenis takaran pemakaian lapis aspal. Sedangkan Untuk bahan perekat antara lapisan perkerasan lama dengan lapisan perkerasan baru, maka penyebaran tack coat harus merata untuk menutup seluruh lapisan. Iilustrasi model dari perkerasan Gambar 1.

Tabel 1. Takaran Pemakaian Lapis Perekat (Bina Marga, 2010)

\begin{tabular}{lccc}
\hline \multicolumn{1}{c}{ Jenis Aspal } & \multicolumn{3}{c}{ Takaran (liter per meter persegi) pada } \\
& $\begin{array}{c}\text { Permukaan Baru atau } \\
\text { Aspal Beton Lama } \\
\text { Yang Licin }\end{array}$ & $\begin{array}{c}\text { Permukaan Porous } \\
\text { dan Terekpos } \\
\text { Cuaca }\end{array}$ & $\begin{array}{c}\text { Permukaan Berbahan } \\
\text { Pengikat Semen }\end{array}$ \\
\hline Aspal Cair & 0,15 & $0,15-0,35$ & $0,2-1,0$ \\
$\begin{array}{l}\text { Aspal Emulsi } \\
\text { Aspal Emulsi }\end{array}$ & 0,20 & $0,20-0,50$ & $0,2-1,0$ \\
yang \\
diencerkan(1:1)
\end{tabular}

Gambar 1. Ilustrasi model perkerasan jalan

\section{Tegangan Geser Pada Perkerasan Jalan}

Pada konstruksi jalan yang sudah berkurang kinerjanya perlu ditingkatkan dengan melakukan overlay atau pelapisan tambahan. Tetapi sebelum overlay dilakukan, perkerasan lama dilapisi terlebih dahulu dengan suatu lapis perekat atau tack coat.Tack coat akan memberikan daya ikat antara lapis perkerasan lama dan lapis perkeasan baru membentuk satu kesatuan lapis perkerasan. Daya ikat ini diperlukan untuk menahan tegangan geser yang terjadi antara lapisan perkerasan lama dan lapisan perkerasan baru akibat adanya beban kendaraan yang lewat di atas lapis perkerasanyang melakukan percepatan atau perlambatan.Kekuatan geser diartikan sebagai daya ikat antar lapis perkerasan (Toad, Joice, \& Waani, 2016)

\section{Kuat Geser}

Kekuatan geser diartikan sebagai daya ikatantar lapis perkerasan yang 
Angraini, M., Saleh, A., Rahmat, H. / Kajian pengaruh Sebaran Tack Coat/ pp. 23-30

memberikan kekuatan untuk melawan pengaruh gaya geser dari beban kendaraan yang bekerja di atasnya. Gaya geser ini terjadi akibat adanya beban kendaraan yang lewat di atas lapisperkerasan, khususnya pada lokasi dimana kendaraan sering melakukan percepatan dan perlambatan(Mentang et al., 2014)

Adanya beban kendaraan yang melewati suatu perkerasan jalan akan mengakibatkan terjadinya gaya geser dan momen lentur pada lapis perkerasan tersebut. Momen lentur yang terjadidiakibatkan adanya gaya tarik pada tepi bawah lapisan beraspal. Sedangkan gaya geser terjadi akibat adanya percepatan atauperlambatan laju kendaraan. Pada strukturperkerasan, agar tidak terjadi slip antar lapisan pada struktur perkerasan, gaya geser yang timbul harus mampu ditahan oleh ikatan pada interface antar lapisan. Untuk tujuan tersebut tack coat biasanya digunakan. Pemberian tackcoat pada bidang kontak antar lapisan (interface) dimaksudkan untuk meningkatkan daya lekat (adhesi) dua lapisan agar menjadi satu kesatuan (Verani \& Sihombing, 2014)

\section{METODE PENELITIAN}

Tempat atau lokasi penelitian dilakukan di Laboratorium Teknik Sipil
Universitas Lancang Kuning dan UPT Balai Pengujian Material Dinas Bina Marga Provinsi Riau. Untuk mengukur kuat geser tack coat padabenda uji beraspal, digunakan alat uji geserlangsung (direct shear) yang dimodifikasi. Alat uji geser langsung yang digunakan sama dengan yang biasa dilakukan untuk mendapatkan parameter geser tanah. Larutan tack coat digunakan dari asphalt cement (AC) pen 60/70 pada larutan aspal 25 pph (25 bagian minyak tanah terhadap 100 bagian aspal) dengan kadar aspal optimum 5,52\%.

\section{HASIL DAN PEMBAHASAN}

\section{Hasil Penelitian}

Pengujian dilakukan masing masing sebaran tack coat yaitu 0,25 ; 0,$30 ; 0,35 ;$ dan $0,451 \mathrm{tr} / \mathrm{m}^{2}$ dibuat 2 sampel, dari masing - masing sampel diambil rata - rata nilai kuat gesernya, dan Hasil pengujian kuat geser tack coat dari aspal penetrasi 60/70 untuk variasi sebaran tack coatyaitu0,25;0,30;0,35; dan $0,45 \mathrm{ltr} / \mathrm{m}^{2}$. (Tabel 2). Nilai kuat geser yang didapat dari uji laboratorium yaitu uji geserlangsung (direct shear) yang dimodifikasi, dituangkan dalam bentuk grafik.Seperti terlihat pada gambar 2, Grafik hubungan antara sebaran tack coat dengan kuat geser tack coat.

Tabel 2. Hasil Pengujian Kuat Geser Tack Coat

\begin{tabular}{lll}
\hline Sebaran tack Coat $\left(\mathbf{I t r} / \mathbf{m}^{\mathbf{2}}\right)$ & \multicolumn{1}{c}{ Kuat Geser $(\mathbf{K g})$} & Rata-rata $(\mathbf{K g})$ \\
\hline $\mathbf{0 , 2 5}$ & 282,46 & 284,14 \\
& 285,81 & \\
$\mathbf{0 , 3 0}$ & 301,82 & 303,97 \\
& 306,12 & \\
$\mathbf{0 , 3 5}$ & 311,52 & 312,83 \\
& 314,13 & 302,06 \\
$\mathbf{0 , 4 5}$ & 301,01 & \\
\hline
\end{tabular}




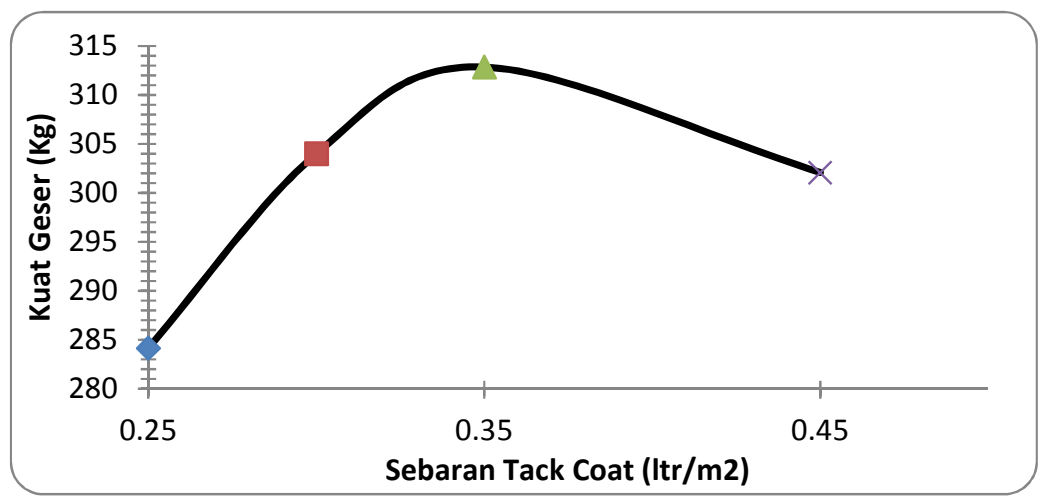

Gambar 2. Hubungan Sebaran Tack Coat dengan kuat geser

\section{Pembahasan}

Dari pengujian kuat geser dengan menggunakan uji geserlangsung (direct shear) yang dimodifikasi, dengan menggunakan variasi sebaran tack coat yaitu 0,$25 ; 0,30 ; 0,35$; dan $0,45 \mathrm{ltr} / \mathrm{m}^{2}$. Dari grafik diatas dapat dilihat nilai kuat geser makin naik setiap penambahan sebaran tack coat yaitu dari sebaran 0,25 $1 \mathrm{tr} / \mathrm{m}^{2}$ sampai sebaran $0,35 \mathrm{ltr} / \mathrm{m}^{2}$. Kuat geser pada sebaran tack coat $0,45 \mathrm{ltr} / \mathrm{m}^{2}$ menjadi turun. Spesifikasi Umum DepartemenPekerjaan Umum Dirjen Bina Marga tahun 2010, takaran sebesar $0,15-0,35 \mathrm{ltr} / \mathrm{m}^{2}$ untuk permukaan porous. Sesuai dengan standar spesifikasi Umum DepartemenPekerjaan Umum Dirjen Bina Marga tahun 2010. Lewat dari sebaran standar nilai kuat gesernya akan turun.

Nilai kuat geser meningkat sampai pada sebaran takaran tack coat 0,35 $1 \mathrm{tr} / \mathrm{m}^{2}$, kemudian turun pada takaran tack coat $0,45 \mathrm{ltr} / \mathrm{m}^{2}$. Semakin tinggi sebaran takaran tack coat maka semakin tinggi kuat gesernya, dan nilainya akan turun sampai batas takaran sebaran tack coat optimum yang disarankan Bina Marga tahun 2010, yaitu $0,35 \mathrm{ltr} / \mathrm{m}^{2}$ untuk permukaan porous.

\section{E. KESIMPULAN}

Semakin tinggi sebaran takaran tack coat maka semakin tinggi kuat gesernya, dan nilainya akan turun pada takaran tack coat $0,45 \mathrm{ltr} / \mathrm{m}^{2}$.

\section{DAFTAR PUSTAKA}

Afrilianto Eko, 2001, Pengukuran Kuat Geser Lapisan Tack Coat Dengan Alat Marshall Yang dimodifikasi, Tesis, Program Pascasarjana Institut Teknologi Bandung, Bandung.

Direktorat Jenderal Bina Marga, Spesifikasi Umum Binamarga 2010 Revisi 3, Kementrian Pekerjaan Umum Direktorat Jenderal Bina Marga.Jakarta

Mentang, S., Somple, B.F., Jansen,F, 2014,Kajian Pengaruh Air Terhadap Kekuatan Geser tack Coat Pada Perkerasan Lentur, Jurnal Ilmiah Media Engineering, Vol.4 No.4, ISSN: 2087-9334.

Sihombing, Rouly A.V, 2014,Pengaruh Temperatur Terhadap Daya Rekat Tack Coat, Jurnal; JalanJembatan, Volume 31 No.1.

Sukirman, Silvia, 2003, Beton Aspal Campuran

Panas, Granit,Bandung. 
Angraini, M., Saleh, A., Rahmat, H. / Kajian pengaruh Sebaran Tack Coat/ pp. 23-30

Toad, W., Waani., E, Joice,2016,

Perkerasan Lentur, Jurnal Ilmiah Kajian Pengaruh Suhu Media Engineering, Vol.6No.1

Permukaan Jalan Terhadap

Kekuatan Geser tack Coat Pada 